\title{
Video demonstration of the ColubrisMX ELS robotic system for local excision and suture closure in a preclinical model
}

\author{
S. Atallah ${ }^{1,2}$ (D) A. Sanchez ${ }^{2} \cdot$ E. Bianchi ${ }^{1,2} \cdot$ S. Larach $^{1,2}$
}

Received: 26 May 2021 / Accepted: 12 June 2021 / Published online: 29 June 2021

(c) Springer Nature Switzerland AG 2021

Next-generation surgical platforms are being retooled to access specific organ systems and targets which are difficult to reach with laparoscopy and current, linear robotic systems [1, 2]. The EndoLuminal Surgical System (ELS, ColubrisMX, Houston, TX, USA) is a non-linear robotic platform with open console configuration that is currently undergoing initial clinical evaluation in North and South America.

In this video, ELS is used to perform local excision of a simulated $3.5 \mathrm{~cm}$ lesion using a porcine model. The ex vivo, preclinical operation was conducted in 58 min, including sutured closure of the porcine wall defect. The details of operation as well as theoretical advantages of the system and its design are highlighted.

Supplementary Information The online version contains supplementary material available at https://doi.org/10.1007/s10151-021-02490-z.

\section{Declarations}

Conflict of interest Dr. Atallah is a consultant and trial principle investigator for ColubrisMX. This study was completed without funding. Dr. Alex Sanchez is a research coordinator who receives fees for activity related to ColubrisMX ELS devices research. Dr. Larach and Bianchi have no financial disclosures to report.

Ethical Approval This research was performed in accordance with the ethical standards of the institutional and/or national research committee and with the 1964 Helsinki declaration and its later amendments or comparable ethical standards.

Informed consent Informed consent was not applicable as the work represented herein did not involve human subjects. Animal research was conducted in accordance with the standards set forth by ethics and scientific laboratory regulations.

\section{References}

1. Keller D, Atallah S, Seela R, Seeliger B, Parra-Davila E (2021) Nonlinear robotics in surgery. Digital Surg. Springer, Cham, pp 285-310

2. Atallah S, Hodges A, Larach SW (2018) Direct target NOTES: prospective applications for next generation robotic platforms. Tech Coloproct 22(5):363-371

Publisher's Note Springer Nature remains neutral with regard to jurisdictional claims in published maps and institutional affiliations.
S. Atallah

atallah@post.harvard.edu

1 UCF College of Medicine, Orlando, FL, USA

2 AdventHealth, Orlando, FL, USA 